\title{
Point-of-care training program on COVID-19 infection prevention and control for pediatric healthcare workers
}

\section{Yingzi Ye}

Children's Hospital of Fudan University

\section{Peng Shi}

Children's Hospital of Fudan University

\section{Yonghao Gui}

Shanghai Medical College,Fudan University

Albert M. Li

Chinese University of Hong Kong

\section{Guoying Huang}

Children's Hospital of Fudan University

\section{Hong Xu}

Children's Hospital of Fudan University

\section{Quan Lu}

Children's Hospital of Shanghai, Shanghai Jiao Tong University

\section{Jianguo Hong}

Shanghai Gengeral Hospital, Shanghai Jiao Tong University

\section{Ying Gu}

Children's Hospital of Fudan University

\section{Xiaojing Hu}

Children's Hospital of Fudan University

\section{Gongbao Liu}

Children's Hospital of Fudan University

\section{Chuanqing Wang}

Children's Hospital of Fudan University

\section{Qing Huang}

Children's Hospital of Fudan University

\section{Xiaobo Zhang ( $\nabla$ xiaobozhang@fudan.edu.cn )}

Children's Hospital of Fudan University https://orcid.org/0000-0002-7666-9638 
Keywords: Awareness , Infection prevention and control, Pediatric healthcare workers, COVID-19, Survey

Posted Date: May 1st, 2020

DOI: https://doi.org/10.21203/rs.3.rs-24793/v1

License: (c) (1) This work is licensed under a Creative Commons Attribution 4.0 International License. Read Full License 


\section{Abstract}

Background: To evaluate the effectiveness of training on knowledge and practices of infection prevention and control (IPC) among pediatric health care workers (HCW) in Shanghai, China, in the context of COVID19 pandemic.

Methods: An online training program was designed by the Shanghai Pediatric Clinical Quality Control Center (SPQCC) during the early phase of COVID-19 pandemic on disease knowledge and practice of IPC. Training took place in the 81 partner hospitals affiliated with SPQCC. A 25-item self-administered questionnaire was used to evaluate knowledge gained from the training. Stratified-random sampling was used to select HCW according to three professionals (i.e., pediatricians, nurses and administrators) within each partner hospital. Awareness and knowledge of COVID-19 and its related infection control and practice was assessed by comparing survey results between different types of hospitals, professionals and professional ranks. A higher survey score meant that the respondent was more prepared and knowledgeable about COVID-19 and its infection control measures.

Results: Completed questionnaires were returned from 1,062 subjects (385 pediatricians, 410 nurses, and 267 administrators), giving a response rate of $96.5 \%$. Overall, awareness of clinical information related to COVID-19, importance of personal hygiene and isolation policy was high among the respondents. No statistical difference of scores on knowledge of COVID-19, IPC and relevant practice between the tertiary and peripheral hospitals. Among all respondents, middle-ranked health care personnel were most knowledgeable and achieved the highest score.

Conclusions: Majority of pediatric HCW showed good recognition and practice in infection protection and control measures. The online training was able to achieve its aim to enhance knowledge and awareness and could have contributed to the zero infection rate among HCW caring for confirmed COVID-19 cases in Shanghai.

\section{Background}

The emergence of severe acute respiratory syndrome coronavirus 2 (SARS-CoV-2; previously provisionally named 2019 novel coronavirus or 2019-nCoV) disease (COVID-19) in China at the end of 2019 has led to a major global outbreak. An important public health problem, COVID-19 is highly infectious and can lead to significant mortality in the elderly and high-risk groups ${ }^{[1-6]}$. So far, it has affected around 1,600,000 persons in 210 countries/ regions with more than 95,000 deaths reported.

Studies have confirmed human-to-human transmission of SARS-CoV-2 ${ }^{[2]}$. The predominant mechanism of transmission is thought to be contact/droplet spread related to respiratory secretions ${ }^{[7]}$. Isolated reports detecting SARS-CoV-2 in stool have also raised concerns about the potential risk of fecal-oral transmission ${ }^{[8]}$. Moreover, according to one study, presumed hospital-related transmission of SARS-CoV2 is suspected in up to $41 \%$ of patients ${ }^{[9]}$. Therefore, to minimize cross-infection and hospital spread of 
this disease adequate awareness of infection prevention and control (IPC) among medical personnel is imperative.

Infection control procedures include administrative logistic arrangements, environmental hygiene, correct work practices and appropriate use of personal protective equipment (PPE). Prompt detection and effective triage and isolation of potential COVID-19 patients are also essential to prevent unnecessary exposure among patients, healthcare personnel and visitors at the hospital. All healthcare facilities must ensure that their personnel are correctly trained and capable of implementing infection control procedures within a short time frame. Individual healthcare personnel should ensure they understand and adhere to strict infection control requirements ${ }^{[10]}$. An effective and easy-to-follow IPC training program that can be accessed off-site to avoid crowd gathering becomes an invaluable tool. As the official pediatric clinical quality control center in Shanghai, we designed an online initiative for healthcare workers (HCW) during the early phase of the pandemic in order to enhance their knowledge and skills in various aspects of IPC in the context of COVID-19. In this study, we evaluated the awareness of HCW on knowledge and practice of infection protection and control following implementation of this initiative.

\section{Methods}

\section{Design of training program}

We developed a 12-minute training video on essential infection protection and control measures. The materials were put together by experts within the Shanghai Pediatric Clinical Quality Control Center (SPQCC), an organization that focuses on improving pediatric medical security and quality led by the Shanghai Municipal Health Commission [11]. The video put a strong emphasis on the correct use of PPE especially the gowning down part which has been documented to be a high risk procedure leading to disease transmission ${ }^{[12]}$. The training video is copyrighted by SPQCC and can be accessed by the following link: https://mp.weixin.qq.com/s/zhYFIHJNQ3euFNmWRneY2A

A written guideline has also been prepared, having taken into account relevant documents from the National Health Commission and the World Health Organization, as well as considering the actual situation in our locality. The guideline consisted of information related to COVID-19, appropriate staff behavior during the pandemic, clinical management and logistics when handling COVID-19 patients, and other operational procedures related to infection control ${ }^{[13]}$.

\section{Implementation of training program}

There are a total of 81 public partner hospitals affiliated with SPQCC and they were all invited to join this program. The partner hospitals included 4 specialized tertiary children's hospitals and 77 general hospitals (28 tertiary and 49 peripheral in service nature). They were requested to arrange for their HCW to 
go through the guideline and training video. The training program was run once a week for three consecutive weeks to ascertain that all HCW had completed the training.

\section{Questionnaire survey}

An online anonymous questionnaire comprised of 25 items was developed to assess the awareness of knowledge and practice of infection control among HCW in our partner hospitals. Demographic and professional information recorded included age, gender, professionals (pediatrician, nurse, and administrator), professional ranks (junior, middle grade or senior), and level of hospital (peripheral or tertiary). The questionnaire consisted of two parts and focused primarily on the knowledge of COVID-19 ( 2 items), the knowledge of personal infection protection and control (13 items) and clinical practice (10 items). The first part was multiple choice questions (10 items) and the second consisted of true / false questions (15 items). (Supplementary file 1). The questionnaire was pre-tested in a convenience sample of $10 \mathrm{HCW}$. Based on their feedback, minor changes were made to enhance clarity and appropriateness of the questions. Four points were given for each correct answer and the total score was 100.

\section{Study participants and sample selection}

The study population consisted of all personnelworking in pediatric healthcare settings engaged in patient care activities and they included pediatricians, nurses and administrators. Latter involved in assisting patient triage, first point of contact to see to patients' requests and provided cleaning and handling of soiled medical supplies or equipments, and they were often in direct contact with potentially contaminated environment.

We used a stratified-random sampling method to select HCW according to three professionals (i.e., pediatricians, nurses and administrators) within each partner hospital of SPQCC. Selected participants were sent an online questionnaire for completion within the same day.

\section{Statistical analysis}

We estimated the sample size using Sample Size Calculators (https://www.sample-size.net/sample-sizeconf-interval-proportion/). As a descriptive study, a minimum sample size of 328 was required taking into account the expected accuracy of the questionnaire to be $>95 \%$ with total width of the confidence interval of $5 \%$. To ensure at least 3 samples within each stratum of three professionals for 81 hospitals, a

total of 729 participants were required in this study to meet the calculated minimum sample size ${ }^{[11]}$. The demographic characteristics of the participants were described as $n(\%), \%)$, and the scores were described as median with IQR. Chi-square test analyses were used to test differences of proportions between peripheral hospitals and tertiary hospitals. Mann-Whitney $U$ test was used to compare the score difference between different hospitals, and Kruskal-Wallis $H$ test was used to compare score difference 
between professionals, and the different ranks. Multiple comparisons were tested using Mann-Whitney $U$ test with bonferroni correction. All data were analyzed using SPSS version 22.0. A p value of $<0.05$ was considered statistically significant.

\section{Results}

\section{Demographics}

Of the 1,100 HCW who were invited to take part, 1062 completed questionnaires were returned, giving a response rate of $96.5 \%$. The median age of the respondents was 32.4 years and $731(71.2 \%)$ were female. A total of $385(36.3 \%)$ pediatricians, 410 (38.6\%) nurses and 267 (25.1\%) administrators were recruited. Among the respondents, $592(55.7 \%)$ and 470 (44.3\%) were from peripheral and tertiary hospital respectively. One hundred thirty-two (12.4\%) responders held senior position, $416 \varangle 39.2 \% \llbracket$ were middle grade and the remaining were junior colleagues (Table 1). Distribution of different HCW from peripheral and tertiary hospitals were similar except number of junior colleagues from tertiary hospital was significantly greater $(54.5 \%$ vs $43.6 \%, \mathrm{P}=0.001)$.

\section{Knowledge and IPC practice among different professional groups}

The median of total score of pediatricians, nurses, and administrators were 96,100 , and 100 respectively. Pediatricians obtained similar score independent of where they worked $(P=0.249)$. Nurses in tertiary practice performed better than those in peripheral hospitals (100 vs $96, P=0.041)$. Administrators in peripheral hospitals got higher score than those in tertiary hospital (100 vs $96, P=0.046)$. In peripheral hospitals, administrators had higher total score than nurses ( 100 vs $96, P=0.027)$ and pediatricians (100 vs $96, P=0.024)$. Whereas, there was no statistical difference in total score among professionals from tertiary hospitals and in all responders. And there was no statistically significant difference in total score of different professional ranks between peripheral and tertiary hospitals, and within the same hospital category. (Table 2).

The questionnaire focused on three categories, namely knowledge of COVID-19 (2 items), knowledge of IPC (13 items) and clinical practice of IPC (10 items). Table 3 shows the 25 items, sub-categories and percentage of accurate response. The accuracy of the items concerned with knowledge COVID-19 was high $(96.0 \%-98.6 \%)$. Likewise, for items that focused on hand hygiene $(96.5 \%-99.6 \%)$. Lower scores were seen on questions about protective clothing and mask, protection in out-patient settings and knowledge of high risk procedures.

Considering scores for individual items, the median with IQR for knowledge on COVID-19 was high $[8(8,8)]$. No differences between hospitals, professionals and ranks were demonstrated. (Table 3.1) 
The median score for knowledge of IPC was 52 (maximum score for this part). There was no significant difference among the scores of pediatricians, nurses and administrators. Middle grade HCW in both peripheral and tertiary hospitals were significantly more likely to obtain maximum score than their juniors. (Table 3.2)

The median score for practice of IPC from the responders was $40(36,40)$. There was no significant difference among scores of pediatricians, nurses and administrators. Middle grade HCW in both peripheral and tertiary hospitals got statistically significant higher score than their junior counterparts. In peripheral hospitals, there was a trend where middle-ranked HCW obtained higher score than their seniors. Among all responders, middle grade HCW out-performed both their juniors and seniors in this category. (Table 3.3)

\section{Discussion}

SARS-CoV-2 has emerged as the cause of an unusual cluster of viral pneumonia in China. This situation has rapidly evolved into a pandemic as declared by the WHO on March 11, $2020^{[14]}$. It is well-established that HCW are at high risk for both acquiring SARS-CoV-2 from patients and transmitting it to patients due to their close proximity, and may contribute to hospital-related COVID-19 outbreaks ${ }^{[15]}$. Our results documented very good knowledge and practice of infection control among healthcare workers in our partner hospitals. Overall, middle grade colleagues had better performance than other ranks in various aspects of infection prevention and control measures.

$\mathrm{HCW}$ are expected to play a leadership role in disseminating targeted preventive strategies and knowledge to the public. However, previous work on their awareness of risks has dominantly been based on attitudes rather than knowledge and practical skills ${ }^{[15-17]}$, so we conducted this questionnaire-based survey to evaluate the effectiveness of training on different aspects of infection control for COVID-19 among pediatric HCW in Shanghai. We had to come up with a simple training package in the context of COVID-19 within a short period of time during the initial phase of this pandemic. As crowd gathering was strongly advised against, online learning became the only medium for information transfer. To enhance information retention and recall, bite-sized, visually stimulating demonstration and simple to understand messages were developed into a video and guideline. These were distributed quickly to our partner hospitals where they would arrange for their $\mathrm{HCW}$ to go through the training within a tight time frame. Time was basically not on our side, total commitment, support from all participating hospitals and a coordinated effort from the center were essential.

The findings revealed good knowledge of information related to COVID-19 among all responders. The result was remarkably better than one observed in a survey that involved non-teaching public hospitals in Italy during epidemics of seasonal influenza ${ }^{[15]}$, and was close to another survey in a teaching hospital in India, which showed that all residents and more than $90 \%$ of nurses knew about transmission modes of influenza ${ }^{[16]}$. Such a high awareness may be due to the increased access to information and knowledge in the last 10 years, including television, internet, scientific journals, and the up-to-date courses with recent 
advance and latest literatures issued by different healthcare authorities. In our case, we believe the practical and applicable guideline and training video most definitely played a major role in enhancing knowledge among our HCW.

We put a strong emphasis on the importance of hand hygiene in preventing hospital-related infections. Various interventions have been carried out in different healthcare settings in Shanghai, for example through educational programs, providing better hand hygiene products, posting reminders on hospital wards, implementing the supervision mechanism and providing incentives. According to our study, the awareness of hand hygiene among HCW was very high, ranging from $96.5 \%$ to $99.6 \%$. And no matter what professional position and rank the HCW held, most had very good recognition of hand hygiene. Our result however, was not consistent with other reports ${ }^{[18-20]}$. Zhang's study showed that nurses have a poor hand hygiene adherence in Beijing, ranging from $21.7 \%$ to $30.0 \%{ }^{[21]}$. To some extent, the findings also illustrated the effectiveness of our training program and various interventions implemented in Shanghai in recent years.

The scores of HCW on COVID-19 knowledge, IPC and relevant practice showed no statistically significant difference between workers from peripheral and tertiary hospitals. Although nurses and administrators had different total scores between tertiary and peripheral hospitals, the difference was probably clinically insignificant. Overall all responders had exhibited very good recognition and knowledge base of all areas tested. The intensive and extensive training had shown its beneficial effects among the pediatric medical staff. Children's Hospital of Fudan University is the designated hospital to receive confirmed COVID-19 cases and at the time of writing we have admitted 18 patients. Though a small number of cases, COVID19 is highly infectious, so far none of our HCW has been infected as a result of hospital spread of disease.

Middle grade professional rank out-performed others in both knowledge and practice of IPC. HCW in China are often classified as "senior", "middle" or "junior" grade according to their skill levels and specialization. As expected, middle grade HCW are often the backbone and main personnel in-charge in clinical activities and they are much more involved in daily clinical routines than senior colleagues, who are usually more administrative orientated. Middle grade colleagues also take on a supervisory role to their junior colleagues. Thus they are more up-to-date with current disease pattern, hot medical topics and it does not therefore come as a surprise that this group of personnel should achieve very high score in this exercise. In fact, many of them might have gone through SARS and are more familiar with IPC measures. Junior colleagues have shorter work experience and limited academic and technical abilities. Our findings underscore the importance to target educational activities to junior colleagues to ascertain their knowledge base would be on par with others.

There are certain limitations in this study. We never conducted a pre-training survey to assess knowledge base of our HCW. There is a possibility that their good knowledge and recognition of IPC had nothing to do with our training program. This may be unlikely as our survey assessed areas related specifically to COVID -19 and topics covered by the training program. Our current study design did not allow 
assessment of longer term knowledge retention and recall. Disease transmission and patient management can be rather different from one disease to another, thus the same program may not be applicable to all emergent conditions. It is more important to be able to respond quickly and design the most appropriate training materials for sharing within a short time frame. In fact, repeated exposure to IPC measures will more likely to encourage retention.

\section{Conclusion}

A targeted online training program put together by a concerted effort had played a significant part to ensure good knowledge of IPC of our HCW and could have contributed to zero infection among HCW caring for COVID-19 cases. Junior colleagues should be specifically earmarked in educational activities to raise their awareness in dealing with any form of emergent diseases.

\section{Abbreviations}

IPC: infection prevention and control; SPQCC: Shanghai Pediatric Clinical Quality Control Center; PPE: personal protective equipment; HCW: healthcare workers.

\section{Declarations}

\section{Ethics approval and consent to participate}

This study was reviewed and approved by the Shanghai Pediatric Clinical Quality Control Center (SPQCC) in a statement that no formal ethics approval was required in this particular case of survey on the awareness of infection prevention and control of healthcare worker. A letter from SPQCC was sent to participants to inform them about the significance and use of the questionnaire and no further consent needed to participates.

\section{Consent for publication}

Not applicable.

\section{Availability of data and materials}

The data collected and analyzed during the current study are available from the corresponding author on reasonable request. 
The authors declare that they have no competing interests.

\section{Funding}

This work was supported by Shanghai Science and Technology Committee (grant number 18411951700).

\section{Author Contributions}

XZ conceptualized and designed the study, supervised all analyses, critically reviewed and revised the manuscript; $Y Y$ designed the study, coordinated and supervised data collection, conducted the data analyses, drafted and revised the manuscript; PS designed the data collection instruments, collected data, carried out the data analyses, and revised the manuscript; $\mathrm{YHG}, \mathrm{AL}$ assisted in data clearing, interpretation of the results and revised the manuscript; $\mathrm{GH}, \mathrm{HX}, \mathrm{QL}, \mathrm{JH}, \mathrm{YG}, \mathrm{XH}, \mathrm{GL}, \mathrm{CW}$ and QH critically reviewed the manuscript for important intellectual content; all authors approved the final manuscript as submitted and agreed to be accountable for all aspects of the work.

\section{Acknowledgements}

Considerable thanks to the Shanghai Pediatric Clinical Quality Control Center and the participants of this study for their valuable contributions and their time.

\section{References}

[1] Lu H, Stratton CW, Tang YW. Outbreak of pneumonia of unknown etiology in Wuhan China: the mystery and the miracle. J Med Virol 2020 Jan 16 [Epub ahead of print]. doi: 10.1002/jmv.25678.

[2] Li Q, Guan X, Wu P, Wang X, Zhou L, Tong Y, et al. Early transmission dynamics in Wuhan, China, of novel coronavirus-infected pneumonia. N Engl J Med 2020 Jan 29 [Epub ahead of print]. doi: 10.1056/NEJMoa2001316.

[3] Huang C, Wang Y, Li X, Ren L, Zhao J, Hu Y, et al. Clinical features of patients infected with 2019 novel coronavirus in Wuhan, China. Lancet 2020;395:497-506.

[4] Holshue ML, DeBolt C, Lingdquist S, Lofy KH, Wiesman J, Bruce H, et al. First case of 2019 novel coronavirus in the United State. N Engl J Med 2020 Jan 31[ Epub ahead of print]. doi:

10.1056/NEJMoa20011191. 
[5] WHO. Novel coronavirus ( 2019-nCoV) situation report 16. World Health Organization, 2020. Ahttps:// www.who.int/docs/default-source/coronaviruse/situation-reports/20200205-sitrep-16-ncov. Pdf? sfvrsn=23af287f_2( accessed Feb 5, 2020)

[6] Chih-Cheng Lai, Tzu-Ping Shih, Wen-Chien Ko, Hung-Jen Tang, et al. Severe acute respiratory syndrome coronavirus 2 (SARS-CoV-2) and coronavirus disease-2019(COVID-19): The epidemic and the challenges. Int J Antimicrob Ag 2020; 7:4-9.

[7] Randy S. Wax, Michael D. Christian. Practical recommendations for critical care and anesthesiology teams caring for novel coronavirus (2019-nCoV) patients. Can J Anesth 2020. Doi: 10.1007/s12630-02001591-x

[8] XINHUANET. Novel coronavirus may spread via digestive system: experts. English.news.cn. http:// www.xinhuanet.com/english/2020-02/02/c_138749620.htm

[9] Wang D, Hu B, Hu C, Zhu F, Liu X, Zhang J, et al. Clinical characteristics of 138 hospitalized patients with 2019 novel coronavirus-infected pneumonia in Wuhan, China. JAMA 2020 Feb 7 [Epub ahead of print]. doi: 10.1001/jama.2020.1585.

[10] Coronavirus Disease 2019 information for healthcare professionals. https://www.cdc.gov/coronavirus/2019-ncov/hcp/index.html

[11] Mei Mei, Hong Xu, Libo Wang, Guoying Huang, et al. Current practice and awareness of pediatric offlabel drug use in Shanghai, China-a questionnaire-based study. BMC Pediatrics 2019; 19:281.

[12] Wolfensberger Aline, Clack Lauren, Kuster Stefan P, Passerini Simone, et al. Transfer of pathogens to and from patients, healthcare providers, and medical devices during care activity-a systematic review and meta-analysis. Infect Cont Hosp Ep 2018;39:1093-107.

[13] Zhang XB, Wang CQ, Zhu QR, Lu Q, et al. Guiding opinions on the quality control of pediatrics in Shanghai about the prevention and control of COVID-19 (Version 1.0). J Fudan University 2020; 47:161-9.

[14] WHO. WHO Director-General's opening remarks at the media briefing on COVID-19-11 March 2020. https://www.who.int/dg/speeches/detail/who-directorgeneral-s-opening-remarks-at-the-mediabriefing-oncovid-19

[15] Luciana Albano, Anna Matuozzo, Paolo Marinelli, Gabriella Di Giuseppe. Knowledge, attitudes and behavior of hospital health-care workers regarding influenza A/H1N1: a cross sectional survey. BMC Infect Dis 2014; 14:208-14.

[16] Puri S, Singh A, Koushal V, Thakare M, et al. Knowledge, attitude and practice regarding the H1N1 pandemic amongst healthcare providers, and preparedness in a multispeciality teaching hospital in North India. Public Health 2011; 125:795-8. 
[17] Obaghe Edeghere, Tom Fowler, Fay Silson, Richard Caspa, et al. Knowledge, attitudes, experience and behavior of frontline health care workers during the early phase of 2009 influenza A (H1N1) pandemic, Birmingham, UK. J Health Serv Res Po 2015;20:26-30.

[18] Qian Z, Miles M. Yang. Yu-Ying Huang, Wenlin Chen. How to make hand hygiene interventions more attractive to nurses: A discrete choice experiment. PLoS One 2018; 13: e0202014.

[19] Liu WI, Liang SY, Wu SFV, Chuang YH. Hand hygiene compliance among the nursing staff in freestanding nursing homes in Taiwan: A preliminary study. Int J Nurs Pract 2014; 20:46-52.

[20] Chen JK, Wu KS, Lee SSJ, Lin HS, et al. Impact of implementation of the World Health Organization multimodal hand hygiene improvement strategy in a teaching hospital in Taiwan. Am J Infect Control $2016 ; 44: 222-7$.

[21] Zhang S, Kong X, Lamb KV, Wu Y. High nursing workload is a main associated factor of poor hand hygiene adherence in Beijing, China: An observational study. Int J Nurs Pract 2019; 25: e12720.

\section{Tables}

Table 1 Demographics and professional characteristics of respondents

\begin{tabular}{|c|c|c|c|c|}
\hline & $\begin{array}{l}\text { Peripheral hospital } \\
\qquad(n=592)\end{array}$ & Tertiary hospital $(n=470)$ & $\begin{array}{c}\text { Total } \\
(n=1062)\end{array}$ & $\mathrm{P}$ \\
\hline Professionals, $n(\%)$ & & & & 0.149 \\
\hline Pediatrician & $215(36.3)$ & $170(36.2)$ & $385(36.3)$ & \\
\hline Nurse & $216(36.5)$ & $194(41.3)$ & $410(38.6)$ & \\
\hline Administrator & $161(27.2)$ & $106(22.6)$ & $267(25.1)$ & \\
\hline Professional rank*, $n$ (\%) & & & & 0.001 \\
\hline Junior & $258(43.6)$ & $256(54.5)$ & $514(48.4)$ & \\
\hline Middle & $260(43.9)$ & $156(33.2)$ & $416(39.2)$ & \\
\hline Senior & $74(12.5)$ & $58(12.3)$ & $132(12.4)$ & \\
\hline
\end{tabular}

*HCW in China are often classified as "senior", "middle" or "junior" grade according to their skill levels and specialization. For example, doctors with senior title refer to chief physician or associate chief physician, middle grade refer to attending physicians and junior title refer to residents ${ }^{[11]}$. 
Table 2 Total score of IPC knowledge and practice, stratified comparison between professionals

\begin{tabular}{|c|c|c|c|c|}
\hline & $\begin{array}{c}\text { Peripheral hospital } \\
\qquad(n=592)\end{array}$ & Tertiary hospital $(n=470)$ & $\begin{array}{c}\text { Total } \\
(n=1062)\end{array}$ & $\overline{\mathrm{P}}$ \\
\hline Average Score & $100(88,100)$ & $100(88,100)$ & $100(88,100)$ & 0.352 \\
\hline \multicolumn{5}{|l|}{ Professionals } \\
\hline Pediatrician & $96(88,100)$ & $100(92,100)$ & $96(88,100)$ & 0.249 \\
\hline Nurse & $96(84,100)$ & $100(91,100)$ & $100(88,100)$ & 0.041 \\
\hline Administrator & $100(92,100)$ & $96(84,100)$ & $100(92,100)$ & 0.046 \\
\hline $\mathrm{P}_{\text {professionals }}$ & 0.012 & 0.341 & 0.323 & \\
\hline $\mathrm{P}$ pediatricians vs nurses & 1.000 & 1.000 & 1.000 & \\
\hline $\mathrm{P}$ pediatricians vs administrators & 0.024 & 1.000 & 0.372 & \\
\hline $\mathrm{P}_{\text {nurses vs administrators }}$ & 0.027 & 0.453 & 0.885 & \\
\hline \multicolumn{5}{|l|}{ Professional rank } \\
\hline Junior & $100(88,100)$ & $100(88,100)$ & $100(88,100)$ & 0.785 \\
\hline Middle & $96(88,100)$ & $100(92,100)$ & $100(88,100)$ & 0.230 \\
\hline Senior & $96(88,100)$ & $98(84,100)$ & $96(88,100)$ & 0.887 \\
\hline $\mathrm{P}_{\text {professional rank }}$ & 0.685 & 0.596 & 0.550 & \\
\hline
\end{tabular}

Table 3 Each item concerned, category and the accuracy of the answers 


\begin{tabular}{|c|c|c|c|}
\hline No. & Item concerns & Categories & Accuracy (\%) \\
\hline 1 & Category III protection: procedure & Knowledge of IPC & 98.9 \\
\hline 2 & Transmission of COVID-19 & Knowledge of COVID-19 & 98.6 \\
\hline 3 & Isolation area & Knowledge of IPC & 89.8 \\
\hline 4 & Category III protection: CT & Knowledge of IPC & 86.8 \\
\hline 5 & Hand hygiene & Knowledge of IPC & 99.6 \\
\hline 6 & Category III protection: outpatient & Knowledge of IPC & 85.7 \\
\hline 7 & Category III protection: high risk procedure & Knowledge of IPC & 96.0 \\
\hline 8 & Use of PPE: isolation Gown & Practice of IPC & 93.1 \\
\hline 9 & Use of PPE & Practice of IPC & 90.4 \\
\hline 10 & High risk procedure & Knowledge of IPC & 84.7 \\
\hline 11 & Hand hygiene & Knowledge of IPC & 98.6 \\
\hline 12 & Indicator to disisolation & Knowledge of COVID-19 & 96.0 \\
\hline 13 & Negative pressure wards & Knowledge of IPC & 99.8 \\
\hline 14 & Disinfection of Goggles & Practice of IPC & 90.8 \\
\hline 15 & Category III protection: collection sample & Knowledge of IPC & 97.4 \\
\hline 16 & Isolation & Knowledge of IPC & 93.5 \\
\hline 17 & Delivery of clinical specimens & Knowledge of IPC & 99.4 \\
\hline 18 & Use of medical protective clothing & Practice of IPC & 85.9 \\
\hline 19 & Use of medical protective mask & Practice of IPC & 83.6 \\
\hline 20 & Use of medical protective mask & Practice of IPC & 99.1 \\
\hline 21 & Use of surgical mask & Practice of IPC & 100.0 \\
\hline 22 & Hand hygiene & Practice of IPC & 96.5 \\
\hline 23 & Use of disposable hat & Practice of IPC & 88.4 \\
\hline 24 & Use of surgical mask & Practice of IPC & 86.8 \\
\hline 25 & Disinfect the environment & Knowledge of IPC & 90.5 \\
\hline
\end{tabular}


Table 3.1 Knowledge of COVID-19, awareness among healthcare workers

(2 items, full mark=8)

\begin{tabular}{lcccc}
\hline & $\begin{array}{c}\text { Peripheral hospital } \\
(n=592)\end{array}$ & Tertiary hospital $(n=470)$ & Total & $\mathrm{P}$ \\
& & & $(n=1062)$ & \\
\hline Average score & $8(8,8)$ & $8(8,8)$ & $8(8,8)$ & 0.685 \\
Professionals & & & & \\
$\quad$ Pediatrician & $8(8,8)$ & $8(8,8)$ & $8(8,8)$ & 0.218 \\
$\quad$ Nurse & $8(8,8)$ & $8(8,8)$ & $8(8,8)$ & 0.481 \\
$\quad$ Administrator & $8(8,8)$ & $8(8,8)$ & $8(8,8)$ & 0.051 \\
$P_{\text {professional role }}$ & 0.757 & 0.073 & 0.609 & \\
Professional rank & & & & \\
Junior & $8(8,8)$ & $8(8,8)$ & $8(8,8)$ & 0.830 \\
Middle & $8(8,8)$ & $8(8,8)$ & $8(8,8)$ & 0.543 \\
Senior & $8(8,8)$ & $8(8,8)$ & $8(8,8)$ & 0.709 \\
P professional title & 0.703 & 0.384 & 0.312 & \\
\hline
\end{tabular}

Table 3.2 Knowledge of IPC, awareness among healthcare workers

(13 items, full mark=52) 


\begin{tabular}{|c|c|c|c|c|}
\hline & $\begin{array}{l}\text { Peripheral hospital } \\
\qquad(n=592)\end{array}$ & Tertiary hospital $(n=470)$ & $\begin{array}{c}\text { Total } \\
(n=1062)\end{array}$ & $\mathrm{P}$ \\
\hline Average score & $52(48,52)$ & $52(48,52)$ & $52(48,52)$ & 0.815 \\
\hline \multicolumn{5}{|l|}{ Professionals } \\
\hline Pediatrician & $52(48,52)$ & $52(48,52)$ & $52(48,52)$ & 0.220 \\
\hline Nurse & $52(48,52)$ & $52(48,52)$ & $52(48,52)$ & 0.288 \\
\hline Administrator & $52(48,52)$ & $52(48,52)$ & $52(48,52)$ & 0.498 \\
\hline $\mathrm{P}_{\text {professionals }}$ & 0.448 & 0.441 & 0.912 & \\
\hline \multicolumn{5}{|l|}{ Professional rank } \\
\hline Junior & $52(48,52)$ & $52(48,52)$ & $52(48,52)$ & 0.812 \\
\hline Middle & $52(52,52)$ & $52(52,52)$ & $52(52,52)$ & 0.514 \\
\hline Senior & $52(48,52)$ & $52(47,52)$ & $52(48,52)$ & 0.665 \\
\hline $\mathrm{P}_{\text {professional rank }}$ & 0.001 & 0.001 & $<0.001$ & \\
\hline $\mathrm{P}_{\text {junior vs middle }}$ & 0.006 & 0.003 & $<0.001$ & \\
\hline $\mathrm{P}_{\text {junior vs senior }}$ & 0.378 & 1.000 & 0.381 & \\
\hline $\mathrm{P}_{\text {middle vs senior }}$ & 1.000 & 0.315 & 0.333 & \\
\hline
\end{tabular}

Table 3.3 Practice of IPC, awareness among healthcare workers (10 items, full mark=40) 


\begin{tabular}{|c|c|c|c|c|}
\hline & $\begin{array}{l}\text { Peripheral hospital } \\
\qquad(n=592)\end{array}$ & Tertiary hospital $(n=470)$ & $\begin{array}{c}\text { Total } \\
(n=1062)\end{array}$ & $\mathrm{P}$ \\
\hline Average score & $40(36,40)$ & $40(36,40)$ & $40(36,40)$ & 0.624 \\
\hline \multicolumn{5}{|l|}{ Professionals } \\
\hline Pediatrician & $40(36,40)$ & $40(36,40)$ & $40(36,40)$ & 0.616 \\
\hline Nurse & $40(36,40)$ & $40(36,40)$ & $40(36,40)$ & 0.443 \\
\hline Administrator & $40(36,40)$ & $40(36,40)$ & $40(36,40)$ & 0.554 \\
\hline $\mathrm{P}_{\text {professional role }}$ & 0.997 & 0.439 & 0.729 & \\
\hline \multicolumn{5}{|l|}{ Professional rank } \\
\hline Junior & $40(32,40)$ & $40(36,40)$ & $40(36,40)$ & 0.543 \\
\hline Middle & $40(40,40)$ & $40(40,40)$ & $40(40,40)$ & 0.739 \\
\hline Senior & $40(36,40)$ & $40(36,40)$ & $40(36,40)$ & 0.983 \\
\hline $\mathrm{P}_{\text {professional rank }}$ & $<0.001$ & 0.001 & $<0.001$ & \\
\hline $\mathrm{P}_{\text {junior vs middle }}$ & $<0.001$ & 0.021 & $<0.001$ & \\
\hline $\mathrm{P}_{\text {junior vs senior }}$ & 1.000 & 1.000 & 0.735 & \\
\hline $\mathrm{P}_{\text {middle vs senior }}$ & 0.051 & 0.252 & 0.009 & \\
\hline
\end{tabular}

\section{Supplementary Files}

This is a list of supplementary files associated with this preprint. Click to download.

- 5.Appendixfilesresubmit20200410.docx 